\title{
Current Cigarette Smoking, Access, and Purchases from Retail Outlets Among Students Aged 13-15 Years - Global Youth Tobacco Survey, 45 Countries, 2013 and 2014
}

\author{
Denise D’Angelo, $\mathrm{MPH}^{1}$; Indu B. Ahluwalia, $\mathrm{PhD}^{1}$; Eugene Pun, $\mathrm{MPH}^{1}$; Shaoman Yin, $\mathrm{PhD}^{2}$; Krishna Palipudi, $\mathrm{PhD}^{1}$; Lazarous Mbulo, PhD ${ }^{1}$
}

Tobacco use is a leading preventable cause of morbidity and mortality, with nearly 6 million deaths caused by tobacco use worldwide every year (1). Cigarette smoking is the most common form of tobacco use in most countries, and the majority of adult smokers initiate smoking before age 18 years $(2,3)$. Limiting access to cigarettes among youths is an effective strategy to curb the tobacco epidemic by preventing smoking initiation and reducing the number of new smokers $(3,4)$. CDC used the Global Youth Tobacco Survey (GYTS) data from 45 countries to examine the prevalence of current cigarette smoking, purchase of cigarettes from retail outlets, and type of cigarette purchases made among school students aged 13-15 years. The results are presented by the six World Health Organization (WHO) regions: African Region (AFR); Eastern Mediterranean Region (EMR); European Region (EUR); Region of the Americas (AMR); South-East Asian Region (SEAR); and Western Pacific Region (WPR). Across all 45 countries, the median overall current cigarette smoking prevalence among students aged 13-15 years was $6.8 \%($ range $=1.7 \%$ [Kazakhstan] $-28.9 \%$ [Timor-Leste $]$; the median prevalence among boys was $9.7 \%(2.0 \%$ [Kazakhstan]-53.5\% [Timor-Leste]), and among girls was $3.5 \%(0.0 \%$ [Bangladesh]-26.3\% [Italy]). The proportion of current cigarette smokers aged 13-15 years who reported purchasing cigarettes from a retail outlet such as a store, street vendor, or kiosk during the past 30 days ranged from 14.9\% [Latvia] to $95.1 \%$ [Montenegro], and in approximately half the countries, exceeded 50\%. In the majority of countries assessed in AFR and SEAR, approximately $40 \%$ of cigarette smokers aged 13-15 years reported purchasing individual cigarettes. Approximately half of smokers in all but one country assessed in EUR reported purchasing cigarettes in packs. These findings could be used by countries to inform tobacco control strategies in the retail environment to reduce and prevent marketing and sales of tobacco products to youths (5).

GYTS is a nationally representative school-based, paper-andpencil, cross-sectional survey of students in school grades associated with ages 13-15 years. GYTS uses a standardized methodology*

\footnotetext{
*The Global Youth Tobacco Survey uses a two-stage sample design to select schools with a probability of selection proportional to enrollment size. The classes within selected schools are chosen randomly and all students in selected classes are eligible to participate in the survey.
}

that allows cross-country comparisons ( 6 ). Forty-five countries in which the GYTS is implemented had data available for 2013 or 2014 and were included in this report. Current cigarette smoking was defined as a report by a student that they had smoked cigarettes on at least 1 day in the past 30 days. Among current cigarettes smokers, cigarette purchasing from a retail outlet was defined for the majority of countries as a report of having purchased them from a store or shop, a street vendor, or a kiosk in response to the question: "The last time you smoked cigarettes during the past 30 days, how did you get them?" Past 30-day purchase of cigarettes in packs or as individual sticks was also assessed among current cigarette smokers. Data were weighted for each country to yield nationally representatives estimates. Country-specific prevalence estimates with corresponding 95\% confidence intervals were calculated, overall and by sex. Estimates based on sample sizes $<35$ or relative standard error $>30 \%$ are not shown. A Wilcoxon rank sum test was used to compare the median prevalence estimates between boys and girls in each country. Overall sample sizes ranged from 526 (San Marino [EUR]) to 9,694 (Bosnia and Herzegovina [EUR]). Response rates ranged from $61.5 \%$ (Pakistan [EMR]) to 100\% (Bangladesh [SEAR]).

Cigarette smoking prevalences among youths aged 13-15 years by WHO region ranged from $2.3 \%$ (Mozambique) to $11.2 \%$ (Zimbabwe) in AFR, from 3.3\% (Pakistan) to $11.4 \%$ (Jordan) in EMR, from $1.7 \%$ (Kazakhstan) to $23.4 \%$ (Italy) in EUR, from $3.8 \%$ (Bahamas) to $7.8 \%$ (Belize) in AMR, from $2.1 \%$ (Bangladesh) to $28.9 \%$ (Timor-Leste) in SEAR, and from $2.5 \%$ (Vietnam) to $11.0 \%$ (Northern Mariana Islands) in WPR. Across all countries, the median overall current cigarette smoking prevalence was $6.8 \%$ (range $=1.7 \%$ [Kazakhstan] $-28.9 \%$ [Timor-Leste]); the median prevalence among boys was $9.7 \%$ (2.0\% [Kazakhstan]-53.5\% [Timor-Leste]), and among girls was 3.5\% (0\% [Bangladesh]-26.3\% [Italy]) (Table).

In 26 of the 45 countries, approximately half of current cigarette smokers aged 13-15 years reported purchasing cigarettes from a retail outlet in the past 30 days (Figure); this proportion ranged from $14.9 \%$ in Latvia to $95.1 \%$ in Montenegro. The proportion of current cigarette smokers who reported buying cigarettes in packs ranged from 15.2\% in Bangladesh to $89.8 \%$ in Serbia, and the proportion of who reported buying cigarettes as individual sticks ranged from $3.6 \%$ in Greece to $84.8 \%$ in Bangladesh (Table). 
TABLE. Prevalence of current cigarette smoking and proportion of current smokers who purchased cigarettes in packs or individually among students aged 13-15 years - 45 countries, Global Youth Tobacco Survey, 2013-2014

\begin{tabular}{|c|c|c|c|c|c|c|}
\hline \multirow[b]{2}{*}{ WHO Region/Country (survey year) } & \multicolumn{4}{|c|}{ Current cigarette smokers } & \multicolumn{2}{|c|}{ Cigarette purchases among current smokers } \\
\hline & $\begin{array}{l}\text { Unweighted } \\
\text { sample size }\end{array}$ & $\begin{array}{c}\text { Total } \\
\%(95 \% \mathrm{Cl})\end{array}$ & $\begin{array}{c}\text { Male } \\
\%(95 \% \mathrm{Cl})\end{array}$ & $\begin{array}{c}\text { Female } \\
\%(95 \% \mathrm{CI})\end{array}$ & $\begin{array}{c}\text { Pack } \\
\%(95 \% \mathrm{Cl})\end{array}$ & $\begin{array}{c}\text { Individual cigarettes } \\
\%(95 \% \mathrm{Cl})\end{array}$ \\
\hline \multicolumn{7}{|l|}{ African Region } \\
\hline Algeria (2013) & 3,921 & $5.7(4.6-7.0)$ & $12.2(9.8-15.2)$ & $0.8(0.4-1.6)$ & $30.0(20.4-41.9)$ & $59.7(50.3-68.4)$ \\
\hline Cameroon (2014) & 1,772 & $5.7(3.4-9.4)$ & $8.3(5.0-13.4)$ & $2.5(1.4-4.3)$ & $30.8(20.1-43.9)$ & $44.8(27.9-62.9)$ \\
\hline Gabon (2014) & 760 & $5.2(3.9-6.8)$ & $6.1(4.5-8.3)$ & $4.0(2.2-6.9)$ & - & - \\
\hline Kenya (2013) & 1,270 & $4.9(3.2-7.6)$ & $7.4(4.5-11.7)$ & $2.6(1.3-3.9)$ & $19.2(8.8-37.0)$ & $51.0(30.2-71.4)$ \\
\hline Mozambique (2013) & 2,804 & $2.3(1.6-3.4)$ & $2.1(1.2-3.5)$ & $2.3(1.4-3.8)$ & - $^{*}$ & - \\
\hline Senegal (2013) & 751 & $4.5(2.6-7.7)$ & $4.7(2.6-8.5)$ & $3.1(1.2-7.6)$ & -* & —* \\
\hline Togo (2013) & 2,740 & $4.8(3.5-6.6)$ & $7.4(5.3-10.3)$ & $1.2(0.7-2.0)$ & $33.2(18.8-51.6)$ & $45.0(31.1-59.7)$ \\
\hline Zimbabwe (2014) & 4,438 & $11.2(6.9-17.8)$ & $11.3(6.9-17.9)$ & $8.9(5.2-14.8)$ & $23.1(14.6-34.6)$ & $22.6(17.3-28.9)$ \\
\hline \multicolumn{7}{|l|}{ Eastern Mediterranean Region } \\
\hline Djibouti (2013) & 1,190 & $6.6(4.5-9.6)$ & $8.0(5.3-11.8)$ & $4.2(2.1-8.4)$ & $40.9(28.8-54.3)$ & $38.6(25.6-53.4)$ \\
\hline Egypt (2014) & 1,973 & $4.8(2.7-8.6)$ & $8.3(3.9-16.5)$ & $0.8(0.3-2.0)$ & $30.9(10.7-62.5)$ & $69.1(37.5-89.3)$ \\
\hline Gaza (2013) & 1,476 & $6.5(4.4-9.6)$ & $9.7(6.8-13.6)$ & $3.5(2.5-4.9)$ & $34.0(18.7-53.7)$ & $43.8(26.8-62.4)$ \\
\hline Iraq (2014) & 1,181 & $5.7(3.7-8.7)$ & $7.8(4.4-13.7)$ & $3.6(2.4-5.3)$ & $63.2(56.8-69.2)$ & $19.6(10.8-32.9)$ \\
\hline Jordan (2014) & 1,779 & $11.4(8.0-15.9)$ & $17.3(13.0-22.6)$ & $5.4(3.3-8.8)$ & $41.1(28.3-55.2)$ & $42.8(33.5-52.5)$ \\
\hline Lebanon (2013) & 1,126 & $11.3(7.8-16.0)$ & $18.8(12.8-26.6)$ & $5.1(2.9-8.8)$ & $79.4(66.7-88.1)$ & $7.0(2.6-17.6)$ \\
\hline Pakistan (2013) & 5,393 & $3.3(2.3-4.7)$ & $4.8(3.2-6.9)$ & $0.9(0.5-2.0)$ & $39.9(25.2-56.7)$ & $35.2(21.2-52.3)$ \\
\hline Qatar (2013) & 1,627 & $9.8(6.7-14.0)$ & $14.9(11.3-19.6)$ & $4.7(3.0-7.3)$ & $56.5(42.0-70.0)$ & $15.0(6.2-31.8)$ \\
\hline Sudan (2014) & 1,304 & $4.5(3.2-6.4)$ & $6.2(4.2-9.0)$ & $2.2(1.3-3.7)$ & - $^{*}$ & - $^{*}$ \\
\hline United Arab Emirates (2013) & 3,291 & $6.2(4.5-8.6)$ & $9.7(6.9-13.4)$ & $2.7(1.6-4.6)$ & $66.9(57.6-75.1)$ & $13.9(8.9-21.0)$ \\
\hline Yemen (2014) & 1,529 & $6.8(4.3-10.6)$ & $9.2(5.2-15.8)$ & $2.5(1.3-4.8)$ & $27.4(9.6-57.3)$ & $61.5(32.6-84.1)$ \\
\hline \multicolumn{7}{|l|}{ European Region } \\
\hline Bosnia and Herzegovina (2013) & 9,694 & $11.2(9.5-13.2)$ & $13.4(11.0-16.1)$ & $8.8(7.0-11.2)$ & $85.5(81.7-88.7)$ & $4.1(2.7-6.3)$ \\
\hline Georgia (2014) & 923 & $7.0(4.4-11.1)$ & $9.9(6.0-15.8)$ & $3.8(1.8-7.6)$ & —* & —* \\
\hline Greece (2013) & 3,988 & $10.1(8.3-12.2)$ & $10.3(8.4-12.6)$ & $9.9(8.0-12.2)$ & $68.2(62.2-73.7)$ & $3.6(1.7-7.4)$ \\
\hline Italy (2014) & 1,399 & $23.4(20.8-26.4)$ & $20.6(16.6-25.3)$ & $26.3(22.3-30.8)$ & $\mathrm{n} / \mathrm{a}^{\dagger}$ & $\mathrm{n} / \mathrm{a}^{\dagger}$ \\
\hline Kazakhstan (2014) & 1,685 & $1.7(1.1-2.5)$ & $2.0(1.1-3.7)$ & $1.3(0.8-2.2)$ & - & - \\
\hline Kyrgyzstan (2014) & 3,358 & $2.4(1.6-3.5)$ & $4.0(2.7-5.8)$ & $0.9(0.4-1.8)$ & $47.6(29.5-66.4)$ & $40.9(24.7-59.3)$ \\
\hline Latvia (2014) & 3,891 & $16.8(15.1-18.5)$ & $16.9(14.7-19.3)$ & $16.5(14.3-19.0)$ & $62.5(58.6-66.3)$ & $13.6(9.6-18.9)$ \\
\hline Lithuania (2014) & 2,936 & $19.4(17.0-22.2)$ & $20.0(16.9-23.6)$ & $19.0(16.4-21.8)$ & $79.8(73.5-84.9)$ & $11.6(8.2-16.3)$ \\
\hline Moldova (2013) & 3,379 & $7.2(5.3-9.7)$ & $11.0(7.9-15.2)$ & $3.2(2.1-5.1)$ & 81.7 (72.7-88.2) & $10.6(6.4-17.0)$ \\
\hline Montenegro (2014) & 3,573 & $6.9(3.4-13.5)$ & $10.8(4.6-23.3)$ & $2.8(1.7-4.5)$ & $85.4(67.1-94.4)$ & $5.5(1.9-14.9)$ \\
\hline Romania (2013) & 3,216 & $9.4(7.8-11.3)$ & $10.1(8.2-12.4)$ & $8.5(6.6-10.9)$ & $50.7(42.0-59.3)$ & $44.4(36.1-53.0)$ \\
\hline San Marino (2014) & 526 & $12.9(12.3-13.5)$ & $11.7(10.9-12.6)$ & $14.1(13.3-15.0)$ & - $^{*}$ & - \\
\hline Serbia (2013) & 2,964 & $13.0(10.5-16.1)$ & $12.7(10.3-15.5)$ & $13.3(9.8-17.8)$ & 89.8 (86.1-92.6) & $4.2(2.5-7.0)$ \\
\hline \multicolumn{7}{|l|}{ Region of the Americas } \\
\hline Bahamas (2013) & 984 & $3.8(2.5-5.8)$ & $4.6(2.6-8.1)$ & $2.6(1.4-4.6)$ & - & -* \\
\hline Barbados (2013) & 1,266 & $7.0(5.6-8.8)$ & $8.8(6.7-11.6)$ & $5.0(3.5-7.1)$ & $31.6(19.5-46.7)$ & $26.3(17.6-37.3)$ \\
\hline Belize (2014) & 1,228 & $7.8(6.1-9.9)$ & $10.4(8.0-13.4)$ & $5.4(3.7-7.8)$ & $28.0(20.2-37.4)$ & $50.9(38.2-63.5)$ \\
\hline Costa Rica (2013) & 2,110 & $5.0(3.8-6.6)$ & $5.7(4.2-7.6)$ & $4.3(2.8-6.6)$ & $48.1(30.6-66.1)$ & $29.5(7.6-45.0)$ \\
\hline \multicolumn{7}{|l|}{ South-East Asia Region } \\
\hline Bangladesh (2013) & 3,072 & $2.1(0.9-4.9)$ & $3.4(1.5-7.1)$ & 0.0 & $15.2(4.5-40.4)$ & $84.8(59.6-95.5)$ \\
\hline Bhutan (2013) & 1,318 & $14.0(11.8-16.4)$ & $23.1(19.0-27.6)$ & $6.6(4.8-9.0)$ & $29.0(21.6-37.6)$ & $53.1(42.5-63.3)$ \\
\hline Timor-Leste (2013) & 1,381 & $28.9(22.1-36.9)$ & $53.5(38.5-68.0)$ & $11.0(7.6-15.7)$ & $31.7(17.8-49.7)$ & $44.8(34.8-55.3)$ \\
\hline Indonesia (2014) & 4,144 & $18.3(13.9-23.6)$ & $33.9(26.1-42.7)$ & $2.5(1.4-4.3)$ & $24.6(18.1-32.5)$ & $74.3(66.9-80.5)$ \\
\hline \multicolumn{7}{|l|}{ Western Pacific Region } \\
\hline Brunei Darussalam (2013) & 887 & $8.5(5.0-13.9)$ & $13.4(7.3-23.3)$ & $3.4(1.6-7.2)$ & —* & -* \\
\hline Korea (2013) & 3,385 & $5.2(4.2-6.3)$ & $7.5(5.8-9.7)$ & $2.6(1.9-3.5)$ & $82.9(75.7-88.2)$ & $13.4(9.2-19.2)$ \\
\hline Mongolia (2014) & 5,973 & $3.9(3.2-4.9)$ & $5.9(4.6-7.5)$ & $1.9(1.2-3.1)$ & $38.4(28.8-49.1)$ & $57.1(46.2-67.3)$ \\
\hline Northern Mariana Islands (2014) & 1,661 & $11.0(10.1-11.9)$ & $13.4(12.3-14.5)$ & $8.5(7.2-10.1)$ & $64.8(60.3-69.1)$ & $18.2(14.9-22.1)$ \\
\hline Vietnam (2014) & 3,404 & $2.5(1.7-3.7)$ & $4.9(3.3-7.0)$ & $0.2(0.1-0.8)$ & $33.2(20.3-49.3)$ & $55.7(40.8-69.6)$ \\
\hline
\end{tabular}

Abbreviations: $\mathrm{Cl}=$ Confidence Interval; $\mathrm{WHO}=$ World Health Organization.

* Data suppressed because sample size $<35$.

${ }^{\dagger}$ Italy did not ask this question. 
FIGURE. Proportion of current cigarette smokers aged 13-15 years who purchased cigarettes from a retail outlet* in the past 30 days — Global Youth Tobacco Survey, 45 countries, ${ }^{\dagger}$ 2013-2014

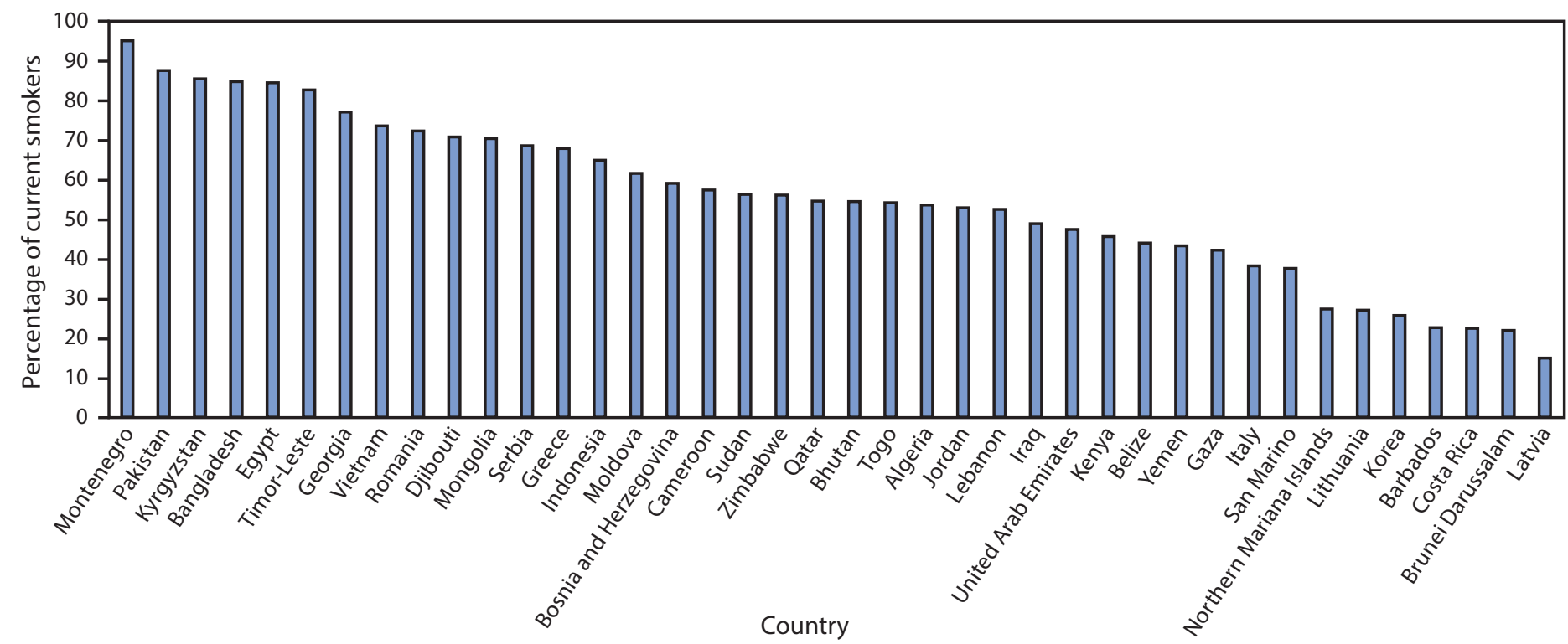

* Retail outlets include store, shop, street vendor, and kiosk. Additional outlets in selected countries are truck stop (Zimbabwe); pharmacy and school canteen (Pakistan); cafeteria (Qatar); gas station and cafeteria (United Arab Emirates); supermarket (Bosnia and Herzegovina and Kazakhstan); small shop and bazaar (Kyrgyzstan); bar, cafe, and restaurant (Moldova); suppliers' house (Brunei Darussalam).

† Data from Bahamas, Gabon, Kazakhstan, Mozambique, and Senegal are suppressed because sample size $<35$.

\section{Discussion}

The overall prevalence of cigarette smoking among students aged 13-15 years in the 45 countries included in this report ranged from 1.7\% (Kazakhstan) to 28.9\% (Timor-Leste). Median smoking prevalence was higher among boys than girls. Prevalence also varied among the countries assessed. Reducing youths' access to tobacco products at retail outlets is an effective strategy to reduce smoking by youths $(3,4)$. The WHO Framework Convention on Tobacco Control (FCTC) is the first international treaty negotiated under the auspices of WHO, developed in response to the globalization of the tobacco epidemic. Demand reduction measures outlined in FCTC have the potential to protect youths from tobacco use and include tobacco tax increases (Article 6) and bans on tobacco advertising, promotions, and sponsorship (Article 13) (7). In addition, supply reduction measures such as addressing illicit trade of tobacco products (Article 15) and prohibition of sale of tobacco products to and by minors (Article 16), also have the potential to reduce the number of youths who smoke (7).

Forty-three of 45 countries that conducted GYTS in 2013 and 2014 have ratified the FCTC. However, varying levels of tobacco control policy implementation and other countryspecific factors can influence cigarette smoking prevalence and access by youths to cigarettes from retail outlets $(7,8)$. Challenges in fully implementing Article 16 might include tobacco industry attempts to undermine access laws that aim

\section{Summary}

What is already known about this topic?

Cigarette smoking is the most common form of tobacco use in most countries, and the majority of adult smokers initiate smoking before age 18 years.

What is added by this report?

Global Youth Tobacco Survey data from 45 countries in 2013 and 2014 identified sex and cross-country differences in prevalence of cigarette smoking among students aged 13-15 years. In most countries, approximately half of youths reported access to cigarettes from a store, street vendor, or kiosk. In the majority of countries assessed in the African and South-East Asia regions, approximately $40 \%$ of smokers aged 13-15 years reported purchasing individual cigarettes.

What are the implications for public health practice?

Tobacco control and prevention policies aimed at youthoriented marketing and sales of tobacco products to youth can help to reduce youths' initiation and use of tobacco products and reverse the global tobacco epidemic.

to reduce use of tobacco among minors, opposition from retailers, poor enforcement, and availability of cigarettes at alternate outlets that are not regulated in some countries (9). The availability of cigarettes for purchase as single sticks, which was common in some countries, makes purchasing less expensive and more attainable for youths, who are generally sensitive to prices (10). 
The variations in the prevalence of cigarette smoking by youths observed by country and by sex might reflect differences in social norms, customs, and adult tobacco use patterns that influence adolescent tobacco use (2), and underscore the potential impact of full implementation of evidence-based interventions outlined in the WHO MPOWER package. ${ }^{\dagger}$ The MPOWER package outlines policies aimed at reversing the global tobacco epidemic, including implementing and enforcing comprehensive smoke-free laws, increasing access to cessation services, warning about the dangers of tobacco use with antismoking media campaigns, and raising taxes to increase the price of tobacco products.

The findings in this report are subject to at least four limitations. First, data were self-reported by students, which might result in misreporting of smoking behavior or tobacco purchasing patterns. Second, students who do not purchase cigarettes themselves might acquire them from other sources such as friends or family. Third, the data presented represent only youths who are enrolled in school, which might limit generalizability to all youths in these countries. Finally, only a limited number of countries were assessed from each WHO region; therefore, the findings in this report do not represent the respective WHO regions overall.

Tobacco prevention and control interventions that restrict youths' access to tobacco products and reduce exposure to youth-oriented tobacco product promotions can reduce tobacco use among youths. Implementing evidence-based measures from FCTC Article 16, in conjunction with evidencebased strategies outlined in WHO's MPOWER package, are critical to reducing the estimated 1 billion tobacco-related deaths projected worldwide this century (1).

\footnotetext{
${ }^{\dagger}$ http://www.who.int/tobacco/mpower/mpower_report_full_2008.pdf.
}

\section{Acknowledgments}

Linda Anton, Global Youth Tobacco Survey Collaborating Group; World Health Organization collaborators.

${ }^{1}$ Office on Smoking and Health, National Center for Chronic Disease Prevention and Health Promotion, CDC; ${ }^{2} \mathrm{CDC}$ Foundation, Atlanta, Georgia.

Corresponding author: Denise D’Angelo, DDAngelo@cdc.gov, 770-488-6288.

\section{References}

1. WorldHealthOrganization. WHOglobal report:mortalityattributableto tobacco, 2012. http://apps.who.int/iris/bitstream/10665/44815/1/9789241564434_ eng.pdf

2. CDC Foundation. Global Adult Tobacco Survey (GATS) atlas, 2015. Atlanta, GA: CDC Foundation; 2016. http://www.cdc.gov/tobacco/ global/gtss/tobacco_atlas

3. US Department of Health and Human Services. Preventing tobacco use among youth and young adults: a report of the Surgeon General. Atlanta, GA: US Department of Health and Human Services, CDC; 2012. http:// www.surgeongeneral.gov/library/reports/preventing-youth-tobacco-use/ full-report.pdf

4. DiFranza JR. Which interventions against the sale of tobacco to minors can be expected to reduce smoking? Tob Control 2012;21:436-42. http://dx.doi.org/10.1136/tobaccocontrol-2011-050145

5. Center for Public Health Systems Science. Point-of-sale strategies: a tobacco control guide. St. Louis, MO: Washington University in St. Louis, Center for Public Health Systems Science, George Warren Brown School of Social Work and the Tobacco Control Legal Consortium; 2014.

6. CDC; Global Youth Tobacco Survey Collaborative Group. Global Youth Tobacco Survey (GYTS): core questionnaire and optional questions, version 1.0. Atlanta, GA: US Department of Health and Human Services, CDC; 2012.

7. World Health Organization. WHO framework convention on tobacco control. Geneva, Switzerland: World Health Organization; 2005. http:// www.who.int/tobacco/framework/WHO_FCTC_english.pdf

8. World Health Organization. 2015. Parties to the WHO framework convention on tobacco control. Geneva, Switzerland: World Health Organization; 2015. http://www.who.int/fctc/signatories_parties/en/

9. Nagler RH, Viswanath K. Implementation and research priorities for FCTC Articles 13 and 16: tobacco advertising, promotion, and sponsorship and sales to and by minors. Nicotine Tob Res 2013;15:832 46. http://dx.doi.org/10.1093/ntr/nts331

10. Linetzky B, Mejia R, Ferrante D, De Maio FG, Diez Roux AV. Socioeconomic status and tobacco consumption among adolescents: a multilevel analysis of Argentina’s Global Youth Tobacco Survey. Nicotine Tob Res 2012;14:1092-9. http://dx.doi.org/10.1093/ntr/nts004 